Chronic Obstructive Pulmonary Diseases: Journal of the COPD Foundation

Images in COPD:

\title{
Combined Pulmonary Fibrosis and Emphysema
}

Maria Elena Vega Sanchez, $\mathrm{MD}^{1}$ Robert Steiner, $\mathrm{MD}^{2}$

\begin{abstract}
Abbreviations: forced expiratory volume in 1 second, $\mathbf{F E V}_{\mathbf{1}}$; forced vital capacity, FVC; total lung capacity, TLC; combined pulmonary fibrosis and emphysema, CPFE; high-resolution computed tomography, HRCT; idiopathic pulmonary fibrosis, IPF;

Citation: Vega Sanchez ME, Steiner R. Images in COPD: Combined pulmonary fibrosis and emphysema. Chronic Obstr Pulm Dis (Miami). 2015;2(4): 367-369. doi: http://dx.doi.org/10.15326/jcopdf.2.4.2015.0162
\end{abstract}

1 Department of Thoracic Medicine and Surgery, Temple University School of Medicine, Philadelphia, Pennsylvania

2 Department of Radiology, Temple University School of Medicine, Philadelphia, Pennsylvania

\section{Address correspondence to:}

Maria E. Vega Sanchez, MD

maria.vegasanchez@tuhs.temple.edu

\section{Keywords:}

combined pulmonary fibrosis and emphysema; high-resolution computed tomography

\section{CASE: An 80 year old male with a 65 pack year history of cigarette smoking presenting with dyspnea on exertion.}

Physical examination was significant for a room air saturation of $92 \%$, crackles on chest auscultation and mild digital clubbing. His pulmonary function test showed evidence of mild airflow obstruction (forced expiratory volume in 1 second $\left(F E V_{1}\right) /$ forced vital capacity (FVC) 58\%, FEV 2.55 liters or 96\%), normal lung volumes (VC 4.45 liters or $118 \%$,total lung capacity [TLC] 6.46 liters or 97\%) and severely decreased diffusing capacity for carbon monoxide (DLCO): $25 \%$. His echocardiogram showed a normal left and right ventricular size and function with no evidence of pulmonary hypertension.
Figure 1. Axial Images of the CT Scan of the Chest A.

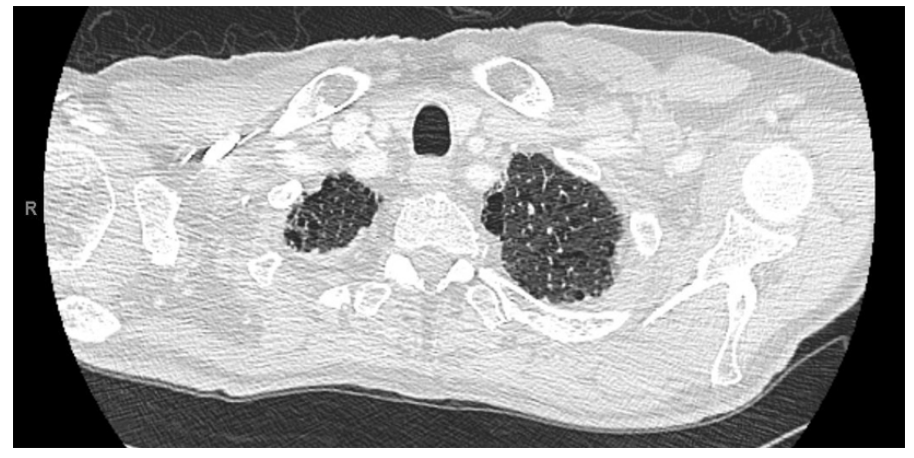

B.

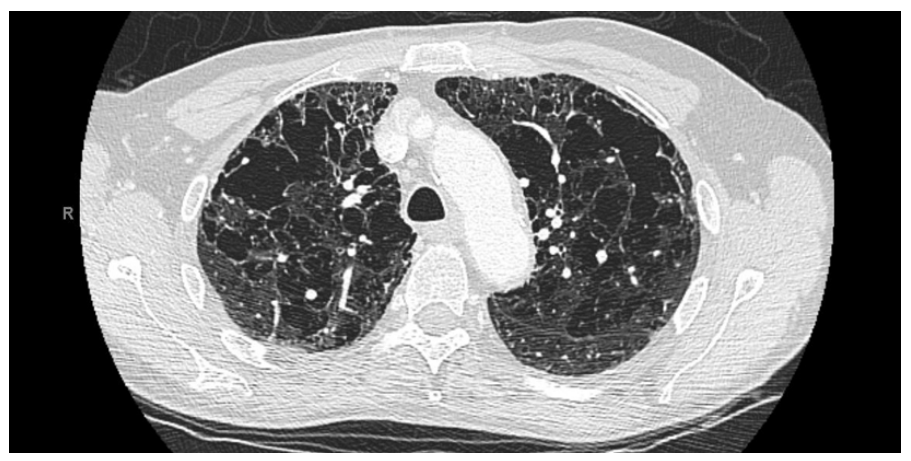

C.

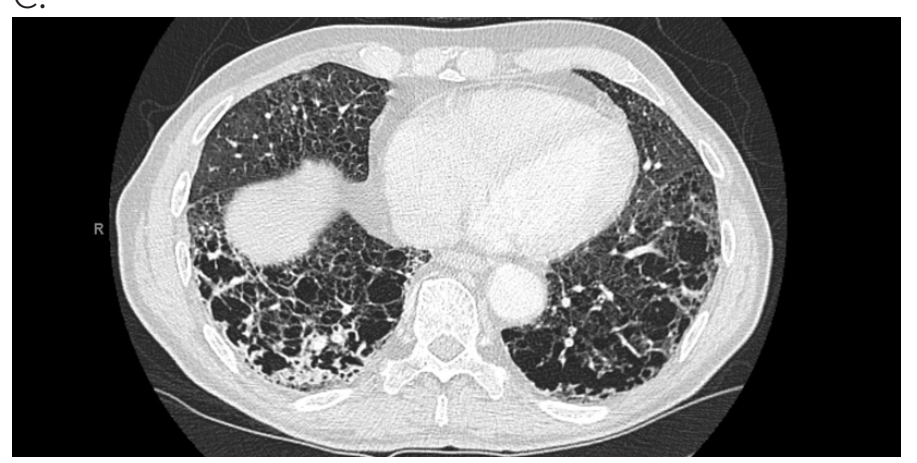


D.

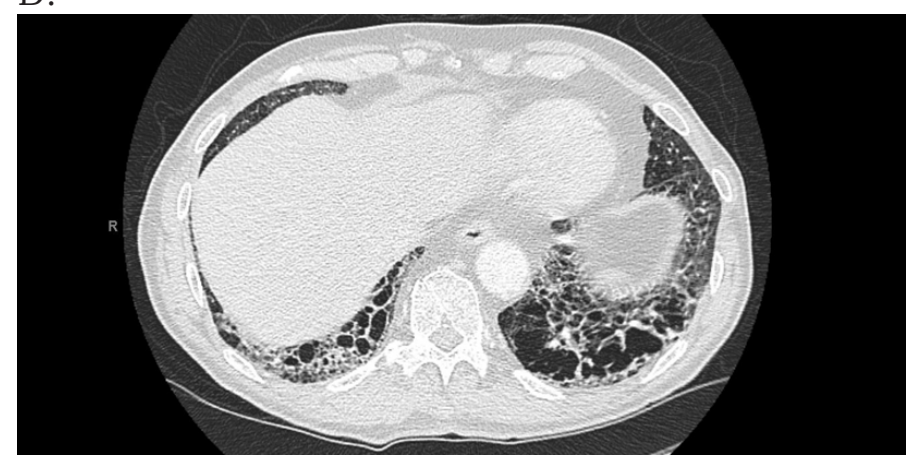

Images A and B: upper zones of the lungs showing predominant paraseptal and centrilobular emphysema. Images $\mathrm{C}$ and $\mathrm{D}$ : lower zones of the lung demonstrating interstitial fibrosis with honeycombing.

\section{Figure 2. Coronal Images of the Chest CT}

A.

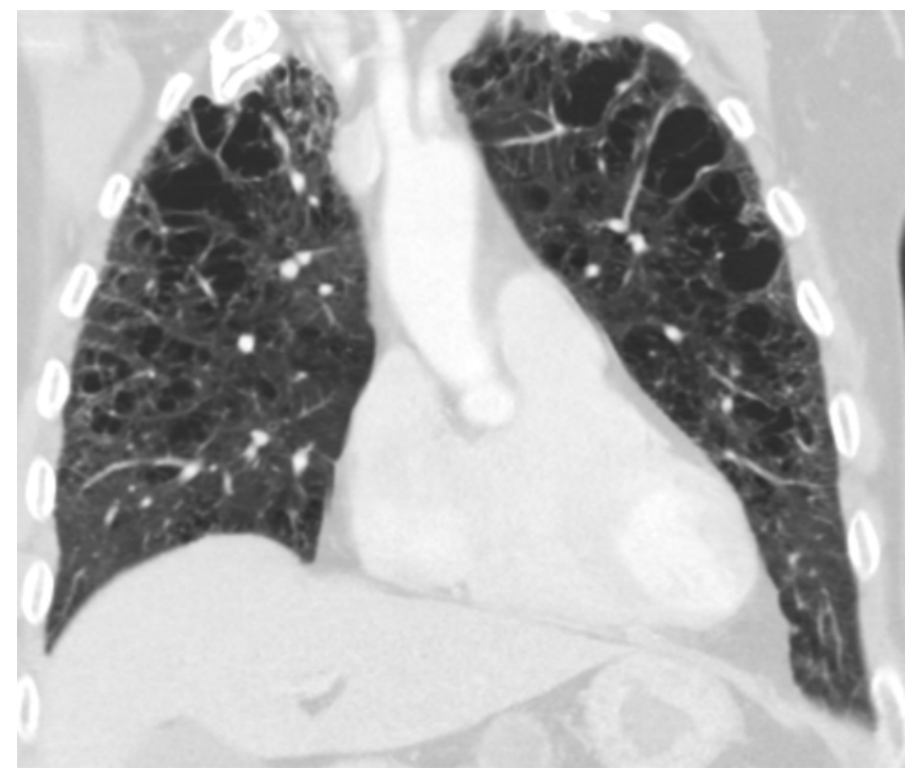

B.

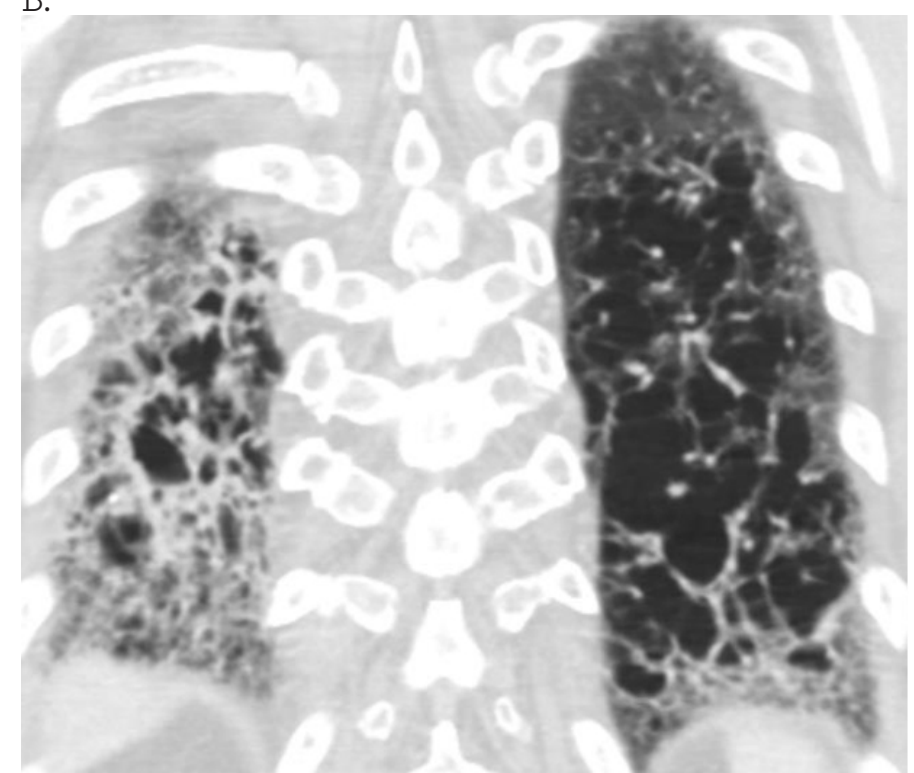

Images A and B: showing upper lobe emphysema and lower lobe pulmonary fibrosis.

\section{Diagnosis : Combined Pulmonary Fibrosis and Emphysema (CPFE)}

The coexistence of pulmonary fibrosis and emphysema results in a clinical syndrome known as combined pulmonary fibrosis and emphysema (CPFE). It predominantly affects older men with significant smoking history, although exposure to agrochemical compounds has also been described in a few cases. ${ }^{1}$ Patients usually complain of dyspnea on exertion and physical examination reveals bibasilar crackles on chest auscultation and digital clubbing. The coexistence of obstructive and restrictive lung disease in patients with CPFE leads to relatively normal spirometry and lung volumes, however, the diffusion capacity is usually severely reduced and may be the only abnormality found on a pulmonary function test. ${ }^{2}$ The diagnosis is established by high-resolution computed tomography (HRCT) which demonstrates upper lobe predominant centrilobular and /or paraseptal emphysema and lower lobe interstitial fibrosis. ${ }^{3} \mathrm{CPFE}$ is associated with a poor prognosis related to the high prevalence of pulmonary hypertension and lung cancer when compared to patients with solitary idiopathic pulmonary fibrosis (IPF) or chronic obstructive pulmonary disease (COPD). ${ }^{4}$ The 1 year survival of CPFE patients with pulmonary hypertension is only $60 \% .^{5}$ There is no specific treatment for patients with this combined syndrome but treatment used for isolated IPF and COPD may be appropriate for patients with CPFE. 


\section{References}

1. Danii Z, Koutsokera A, Gourgoulianis K. Combined pulmonary fibrosis and emphysema in patients exposed to agrochemical compounds. Eur Repir J. 2006;27(2):434. doi: http://dx.doi.org/10.1183/09031936.06.00124505

2. Cottin V,Nunes H,Brillet PY,etal and the Groupe d'Etudeet de Recherché sur les Maladies "Orphelines" Pulmonaires (GERM"O”P). Combined pulmonary fibrosis and emphysema: a distinct underrecognised entity. Eur Respir J. 2005;26:586-593. doi: http://dx.doi.org/10.1183/09031936.05.00021005

3. Portillo K, Morera J. Combined pulmonary fibrosis and emphysema syndrome: A new phenotype within the spectrum of smoking -related interstitial lung disease. Pulmonary Med. 2012 ;2012:1-8. doi: http://dx.doi.org/10.1155/2012/867870

4. Odani K, Yoriko M, Shoji Y. Computed tomographic emphysema with idiopathic pulmonary fibrosis. J Tomography (Japan). 2004; 31(1):25-29.

5. Cottin V, Le Pavec J, Prevot G, et al; GERM”O”P. Pulmonary hypertension in patients with combined pulmonary fibrosis and emphysema syndrome. Eur Respir J. 2010;35(1):105-111.

doi: http://dx.doi.org/10.1183/09031936.00038709 